\title{
periferio
}

\section{AS (RE) AÇÕES DOS PROFESSORES REGENTES E O AUXILIAR PEDAGÓGICO ESPECIALIZADO (APE) NA ESCOLARIZAÇÃO DO ESTUDANTE COM DEFICIÊNCIA}

\author{
Lucimar de Lima Franco ${ }^{1}$ \\ SEMED Campo Grande- MS \\ Celi Corrêa Neres ${ }^{2}$ \\ Universidade Estadual de Mato Grosso do Sul
}

\section{Resumo}

Este estudo objetivou refletir a atuação de professores regentes e do professor especializado na escolarização de um estudante com deficiência em uma escola de Campo Grande, Mato Grosso do Sul. Na Rede Municipal de Ensino (Reme) desse município, esse profissional especializado denomina-se Auxiliar Pedagógico Especializado (APE) e atua juntamente com o professor regente. 0 estudo apresentou caráter exploratório, em que, no campo empírico, buscou-se informações prévias para tatear o objeto e obter dados para sua compreensão. Considerando a política educacional, o esforço concentrou-se na análise dos dados a partir do entendimento da singularidade, a educação especial, integrante da educação geral no âmbito da sociedade. Pautou-se em observações das práticas pedagógicas de 11 (onze) professores regentes e 1 (um) professor especializado, registradas em diário de campo e em entrevistas semiestruturadas, pontuando aspectos da relação educativa, instrumentos de mediação e espaço físico de escolarização. As análises apontaram a necessidade de se repensar o papel do professor APE para que atue como apoio ao trabalho dos professores e não apenas no atendimento ao estudante com deficiência. Indicaram, ainda, que os professores regentes têm consciência de que o estudante com deficiência precisa de práticas diferenciadas, mas não se reconhecem como agente principal na aprendizagem deste, portanto não têm contemplado a participação e progressão do estudante. Concluiu-se que as (re)ações dos professores regentes predominam concepções de que a escolarização de estudantes com deficiência compete ao professor especializado, revelando que ainda não assumiram como seus todos os estudantes.

Palavras-chave: educação especial; estudante com deficiência; sala comum

\footnotetext{
${ }^{1}$ Mestre em educação pela Universidade Estadual de Mato Grosso do Sul (UEMS). Docente da Rede Municipal de Ensino de Campo Grande- MS.

2 Doutora em Educação pela Universidade de São Paulo. Docente do Curso de Pedagogia e do Programa de Pós Graduação, Mestrado Profissional em Educação da Universidade Estadual de Mato Grosso do Sul (UEMS). c.neres@uol.com.br
} 


\title{
periferio
}

\author{
PROFESSOR STEWARD AND THE TEACHING ASSISTANT \\ SPECIALIST (EPA): THEIR RE (ACTIONS) IN STUDENT \\ ENROLLMENT WITH DISABILITIES
}

\begin{abstract}
This study aimed to reflect on the role of school teachers and teacher specialized in the education of students with disabilities in a public school in Campo Grande, Mato Grosso do Sul. In the Municipal Education Network (Reme) that city, this specialized professional called Teaching Assistant Specialist (APE) and acts with teachers. The study had exploratory character, where, in the empirical field, we sought to advance information to grope the object and obtain the data necessary for your understanding. Considering the educational policy, the effort focused on the analysis of data from the understanding of the uniqueness, special education, which is an integral part of general education within the company. Was marked on observations of teaching practice of 11 (eleven) teachers in regular education and 1 (one) special education teacher, recorded in a field diary and semi-structured interviews, punctuating the stories of teachers and aspects of the educational relationship, mediation tools and physical education space. The analysis showed the need to rethink the role of the teacher EPA so that it acts as support the work of conductor teacher, in not only serving the student with a disability. Also indicated that steward teachers are aware that students with disabilities need different practices, but do not recognize themselves as the main agent in student learning, which have not included the participation and progression of the student. It was concluded that the (re) actions of school teachers predominate conceptions that schooling of students with disabilities it is for the specialist teacher, revealing that not assumed as their all students.
\end{abstract}

Keywords: special education; student with disabilities; common room 


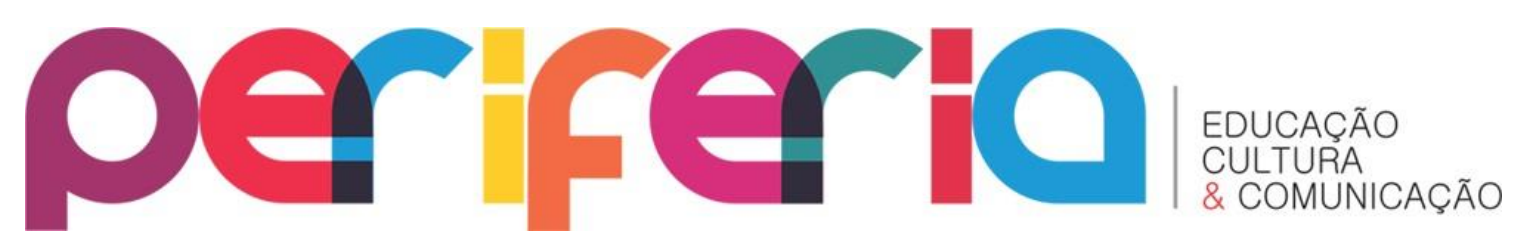

\section{INTRODUÇÃO}

Tradicionalmente, a educação especial se deu em espaços especializados. Somente a partir da década de 1960, a educação dos alunos com deficiência passou a ser ancorada por meio do discurso de integração³; e a partir da década de 1990 , com a proposta da inclusão ${ }^{4}$. Com a referida proposta, a escola comum passa a ser responsável pela escolarização dos estudantes com deficiência, imprimindo novas configurações na ação dos professores.

0 termo integração está presente na Lei $n^{\circ} 4.024 / 1961$, enquanto que a inclusão consta na atual política educacional brasileira, conforme a Política Nacional de Educação Especial na Perspectiva da Educação Inclusiva (BRASIL, 2008a). Cabe-nos refletir a necessidade da atualização desses documentos, pois mesmo com alterações persistem, ainda, os discursos e práticas que muitas vezes revelam segregação.

Atualmente nas escolas, além do professor regente ${ }^{5}$, conta-se com o apoio do professor especializado, este último com a função de mediar os conteúdos propostos pelos primeiros.

A despeito das funções que esses profissionais desempenham, explanadas nas políticas para a Educação Especial, entende-se que as práticas não devem se estabelecer separadamente. Conforme Mendes, Vilaronga e Zerbato (2014, p. 29-30), devem seguir "em direção a uma abordagem que centre nos direitos humanos e que, no caso da Educação, implique em mudanças na organização da escola".

\footnotetext{
${ }^{3} \mathrm{~A}$ integração baseava-se no princípio de normalização, teve origem nos países escandinavos com "[...] pressuposto de que as pessoas com deficiências tinham o direito de conviver socialmente, mas que deviam ser [...] preparadas em função de suas peculiaridades para assumir papéis na sociedade". (MENDES, 2006, p. 389)

4 A proposta de inclusão escolar de crianças e jovens com necessidades educacionais especiais surgiu nos Estados Unidos, ganhando o mundo ao longo da década de 1990. (MENDES, 2006, p. 391)

${ }^{4} \mathrm{O}$ termo professor regente foi utilizado em referência ao professor da escola comum que ministra os componentes curriculares.
} 


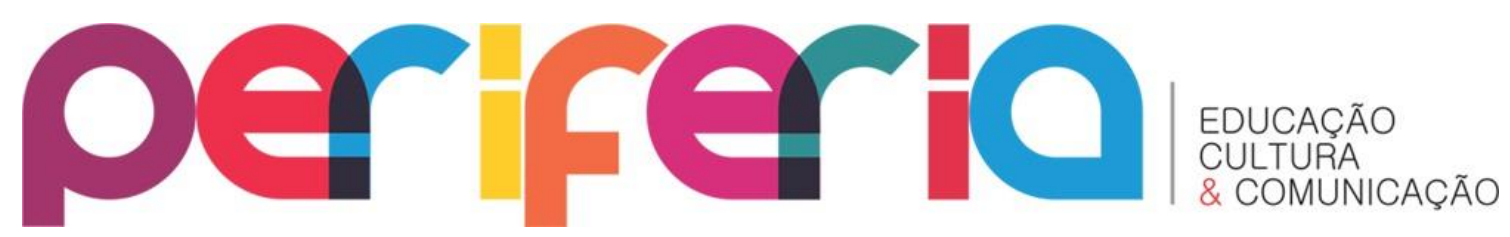

No que tange à escolarização dos estudantes com deficiência, é relevante considerar as especificidades, de modo a favorecer 0 desenvolvimento físico, emocional, intelectual, social e cultural.

Mendes (2002, p. 76), aponta que para a construção de escolas inclusivas haverá "[...] a necessidade de ensino colaborativo ou cooperativo entre professores do ensino regular e especial, [...]”. O que requer mudanças na proposta pedagógica escolar, nas práticas docentes e orientações mais claras das políticas educacionais.

Diante disso, investigou-se as re(ações) dos professores regentes e os auxiliares pedagógicos especializados (APE) na escolarização do estudante com deficiência.

As análises e reflexões tiveram como aporte teórico a categoria histórica “Organização do Trabalho Didático”, proposta por Alves (2005), na qual o autor considera que em cada época configura-se uma relação educativa que coloca frente a frente um educador e estudante, realizada por meio de instrumentos didáticos, num espaço físico.

\section{PROCEDIMENTOS, INSTRUMENTOS E SUJEITOS DA PESQUISA}

A proposta de investigação foi apresentada aos professores, para o consentimento da realização, a fim de que pudéssemos observar as práticas de sala de aula e realizar as entrevistas semiestruturadas, gravadas, transcritas e analisadas.

Investigamos aspectos da relação didática de 11(onze) professores regentes e 01 (um) professor Auxiliar Pedagógico Especializado (APE) do $9^{\circ}$ ano do Ensino Fundamental e das mediações didáticas na escolarização de 01 (um) estudante com deficiência.

Conforme a Resolução Semed n 154/2014, cap. III, art. 23, o professor APE deve: 


\section{periferio}

[...] viabilizar o acesso dos alunos aos conhecimentos e conteúdos curriculares por meio da adequação das atividades [...] planejar, juntamente com o professor regente, as situações de intervenção com responsabilidade compartilhada em sala de aula (CAMPO GRANDE, 2014, p. 4).

A despeito de estar previsto nas orientações, as funções dos profissionais, cabe-nos refletir a viabilização destas, diante das condições concretas da escola.

\subsection{IDENTIFICAÇÃO DOS SUJEITOS DA PESQUISA}

Embora o estudo enfatize as práticas dos professores, ressalta-se, como sujeito indireto, um estudante com deficiência intelectual, paralisia cerebral, comprometimento físico neuromotor, baixa visão e usuário de cadeira de rodas. As deficiências foram informadas por meio de laudos médicos pelo professor especializado que atua na SRMs.

0 estudante é do sexo masculino, tem 20 anos e estuda nessa escola desde o $5^{\circ}$ ano do EF I. Conforme o professor da SRMS, o estudante não frequenta o AEE no contraturno, nem outros apoios especializados, devido ao fato de não ter quem levá-lo. Quanto à inserção em outras atividades escolares, observou-se a prática de esportes adaptados.

Torna-se oportuno destacar que, neste estudo, utilizamos siglas para preservar a identidade do estudante com deficiência, professores regentes e do professor APE. 


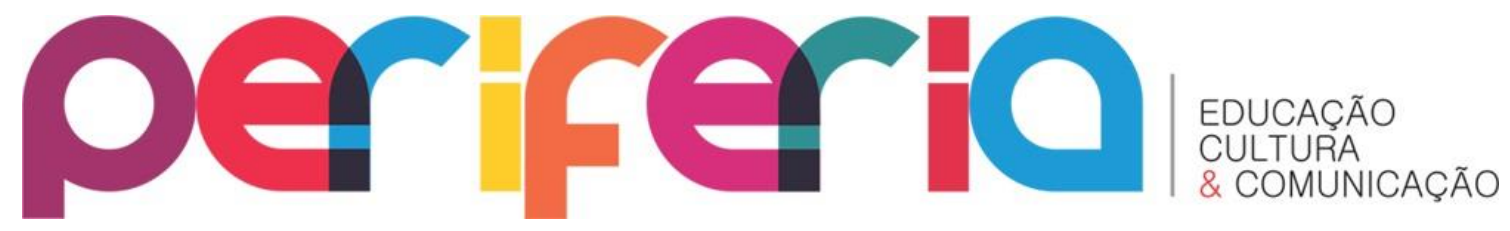

Quadro 1. Perfil dos sujeitos da pesquisa - professores/estudante com deficiência.

\begin{tabular}{|c|c|c|c|}
\hline Profissionais & Pseudônimo & Formação / ano & $\begin{array}{l}\text { Teve disciplinas sobre } \\
\text { Educação Especial na } \\
\text { Graduação? }\end{array}$ \\
\hline \multirow[t]{2}{*}{$\begin{array}{l}\text { Professor de } \\
\text { Língua } \\
\text { Portuguesa }\end{array}$} & \multirow[t]{2}{*}{ PLP } & $\begin{array}{l}\text { L - Letras Português-Inglês } \\
\text { e Respectivas Literaturas } \\
\text { (1999) }\end{array}$ & Não \\
\hline & & L - Pedagogia (2003) & Não \\
\hline $\begin{array}{l}\text { Professor de } \\
\text { Matemática }\end{array}$ & PM & L - Matemática (2004) & Não \\
\hline \multirow{2}{*}{$\begin{array}{l}\text { Professor de } \\
\text { Aplicações } \\
\text { Matemáticas }\end{array}$} & \multirow[t]{2}{*}{ PAM } & $\begin{array}{l}\mathrm{L}-\text { Ciências Físicas e } \\
\text { Biológicas (1996) }\end{array}$ & Não \\
\hline & & L - Matemática (2005) & Não \\
\hline $\begin{array}{l}\text { Professor de } \\
\text { Literatura }\end{array}$ & $\mathrm{PL}$ & $\begin{array}{l}\text { L - Letras Português-Inglês } \\
\text { e Respectivas Literaturas } \\
\text { (não informado) }\end{array}$ & \\
\hline $\begin{array}{l}\text { *Professor de } \\
\text { Língua } \\
\text { Inglesa I e II }\end{array}$ & PLI I-II & $\begin{array}{l}\text { L/B - } \text { Letras Português- } \\
\text { Inglês e } \quad \text { Respectivas } \\
\text { Literaturas (2005) }\end{array}$ & Não \\
\hline $\begin{array}{l}\text { **Professor } \\
\text { de Química }\end{array}$ & $P Q$ & L/B - Ciências (2004) & Não \\
\hline $\begin{array}{l}\text { **Professor } \\
\text { de Física }\end{array}$ & $\mathrm{PF}$ & L/B - Ciências (2004) & Não \\
\hline $\begin{array}{l}\text { Professor de } \\
\text { Geografia }\end{array}$ & PG & L - Geografia (1982) & Não \\
\hline $\begin{array}{l}\text { Professor de } \\
\text { História }\end{array}$ & $\mathrm{PH}$ & L - História (2013) & Educação Inclusiva \\
\hline \multirow{2}{*}{$\begin{array}{l}\text { Professor de } \\
\text { Educação } \\
\text { Física }\end{array}$} & \multirow[t]{2}{*}{ PEF } & LP - Educação Física (2009) & Educação Especial \\
\hline & & 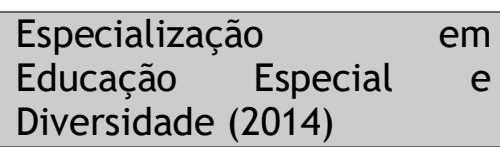 & - \\
\hline $\begin{array}{l}\text { Professor de } \\
\text { Arte }\end{array}$ & PA & L - Arte (2013) & Educação Inclusiva \\
\hline \multirow{3}{*}{$\begin{array}{l}\text { Auxiliar } \\
\text { Pedagógico } \\
\text { Especializado }\end{array}$} & \multirow[t]{3}{*}{ APE } & L - Pedagogia (2007) & Educação Especial \\
\hline & & L - Arte (2012) & Não \\
\hline & & $\begin{array}{l}\text { Especialização } \\
\text { Diversidade e Educação } \\
\text { Especial para a Inclusão } \\
\text { Educacional (2010) }\end{array}$ & - \\
\hline $\begin{array}{l}\text { Estudante } \\
\text { com } \\
\text { deficiência }\end{array}$ & $\mathrm{EA}$ & $\begin{array}{l}9^{\circ} \text { ano do } \text { Ensino } \\
\text { Fundamental II }\end{array}$ & \\
\hline
\end{tabular}




\section{periferio}

\section{ANÁLISES E REFLEXÕES DAS OBSERVAÇÕES E DAS ENTREVISTAS AOS PROFESSORES REGENTES E APE NA ESCOLARIZAÇÃO DO EA}

As entrevistas e as observações permitiram conjecturar sobre a concepção de inclusão escolar que permeia o ideário dos profissionais e fizeram parte das discussões e estudos precedentes.

Os professores explanam as aulas no quadro, com ênfase na escrita, explicações coletivas e utilização do livro didático, da mesma forma que historicamente, se configurou o trabalho didático docente. Conforme Neres (2015, p. 19): "Esse formato cristalizado na escola, não tem favorecido o processo de escolarização dos alunos com deficiência que necessitam de uma ação docente, em alguns momentos, individualizada".

No caso da escolarização de alguns estudantes com deficiência, conforme prevê as orientações para a educação especial, como parte dos apoios especializados, além dos professores regentes, estão presentes outros agentes, nesse estudo, o professor APE. A relação educativa envolve, portanto, dois profissionais que atuam no mesmo espaço físico.

Elencamos 3 eixos de análises, a partir da categoria histórica proposta por Alves (2005), Organização do Trabalho Didático: I. Espaço Físico de escolarização do EA, II. Relação Educativa (Professores Regentes/ professor APE/EA) e III. Instrumentos de mediação didática, descritos a seguir.

\subsection{EIXO I: ESPAÇO FíSICO DE ESCOLARIZAÇÃO DO EA}

A despeito de frequentar a sala comum, o espaço ocupado pelo EA e professor APE era ao fundo da sala. Freitas (2013, p. 94), ao investigar a atuação dos professores de apoio à inclusão, observou que esses profissionais ficavam ao final da sala, "[...] lugar quase invisível, para não atrapalhar as 


\section{periferio}

explicações oferecidas aos demais alunos, o que ele não aprender, o professor de apoio poderá ensinar".

O que revela práticas docentes paralelas no mesmo espaço físico, considerada natural pelo $\mathrm{PH}$ que, ao relatar sobre a interação com o professor APE: "Ela [APE] não chega atrapalhar meu trabalho, nem eu vou atrapalhar o dela $[\ldots] "$.

Os relatos do referido professor reforçam a divisão de funções e espaço que cada profissional ocupa. Quanto ao local do professor APE ao fundo da sala, Freitas (2013) afirma que:

[...] constitui uma inferiorização do seu trabalho que o limita ao atendimento a um único aluno [...]; o professor regente de certo modo se desobriga [...] da responsabilidade com a aprendizagem da criança deficiente [...]. (p. 94-95).

Há necessidade de estabelecer um novo plano de trabalho, com ações conjuntas, que contemplem a participação e progresso do estudante.

O EA não frequenta as aulas de literatura e de PLI I-II, por que estas aulas acontecem nos últimos tempos e nesse horário o EA precisa sair para tomar o ônibus adaptado que o busca às 16:30hrs, portanto, a sala de aula não configura como espaço de escolarização. Observamos que a realização de algumas atividades ocorre em outra aula e/ou outro ambiente da escola com o professor APE. São questões que fogem das atribuições dos professores, ainda não esclarecidas nas políticas públicas que precisam ser discutidas.

Nas aulas de aplicações matemáticas percebemos que o instrumento de mediação não contribuiu para que a sala de aula seja apropriada, este professor faz simulados e precisa de silêncio, como o EA tem limitações na fala, precisa falar várias vezes e alto para ser entendido, assim, EA e professor APE realizam atividades simples em outro ambiente. Conforme o professor APE, o EA: “[...] não tem condições de participar [...] por não possuir [...] esse conteúdo básico [...] sempre que tem que fazer prova, tem 


\section{periferio}

que sair com ele $[\ldots]$ às vezes você tem que perguntar de três, quatro maneiras $[\ldots] "$.

São situações em que a escola não apresenta soluções condizentes com as orientações sobre inclusão escolar, isso nos traz a resposta concreta de que as escolas não realizam a integração, nem a inclusão, pois as metodologias não têm sido pensadas para esses estudantes.

Embora na LDB n 9394/1996 conste que as escolas devem assegurar currículos, métodos, recursos educativos para atender esses estudantes, percebemos as práticas docentes pouco têm se modificado.

Zanata (2004, p. 4) apontou em seus estudos acerca de práticas inclusivas na perspectiva colaborativa que "[...] o professor de classe comum tende a modificar pouco sua prática, [...] de modo que a participação e aprendizagem desses alunos ficam comprometidas".

Ainda que os discursos sobre a inclusão escolar e construção de escolas inclusivas imperem nos documentos oficiais, as condições postas na escola não contribuem para a eficácia das práticas docentes.

No contexto das aulas de geografia, este professor entende que a sala de aula não é local apropriado para o EA desenvolver atividades, ao afirmar que para realizá-las o EA demora "[...] para falar, para racionar, muitas vezes ele (EA) tem que ir para fora [...] tem barulho na sala [...]".

Diante das dificuldades do EA com certos conteúdos, é preciso que os docentes discutam acerca de atividades adequadas, "[...] de forma que os fazeres e saberes, [...] possam se complementar na busca pelo desenvolvimento tanto dos alunos com Def/NEE como dos demais" (HONNEF, 2014, p.15).

Nas aulas de educação física, os espaços de aprendizagem variaram entre sala de aula e quadra. Tendo em vista as limitações do EA, o PEF 


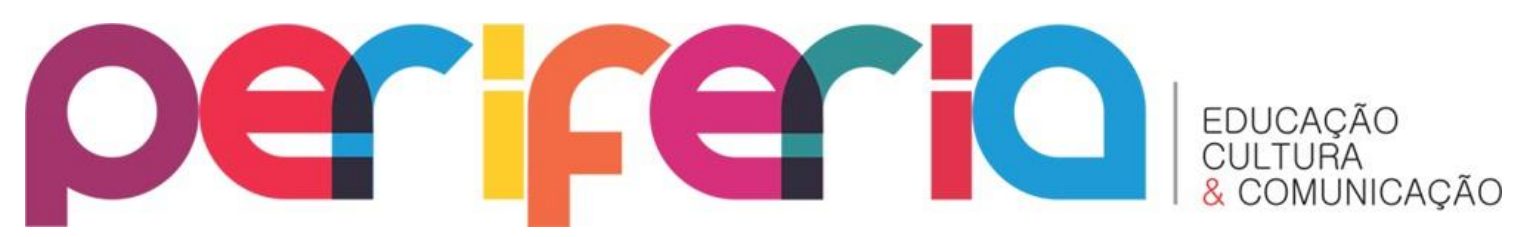

afirmou estar adaptando um esporte denominado "boxa" para contemplar a sua participação nas aulas.

Ao considerar aspectos de espaço físico e realizações de atividades nas aulas de química e física, este professor afirmou que estas aulas são realizadas com "[...] todo mundo junto, interação [...]". Nesse contexto, a sala de aula é enfatizada como local de aprendizagem de todos.

Tendo em vista as limitações motoras e as dificuldades do EA com áreas exatas, o PQ-F privilegia o laboratório de ciências para explanar as aulas de forma concreta, “[...] ele [EA] não pode montar o experimento, mas ele está [...] acompanhando visualmente [...]" (PQ-F). (Entrevista concedida em 15/06/2016)

No contexto das aulas de arte, percebeu-se diversificações feitas por este professor, nas disposições dos estudantes e nos materiais utilizados (vídeos, materiais de pinturas, debates e seminários). Essas diversificações ampliaram as possibilidades de participação do EA e demais estudantes, bem como a forma de avaliação dos professores.

Nas aulas de história, percebemos com os relatos do $\mathrm{PH}$ que, este não considerava a sala de aula como local para o aprendizado do EA, e acredita que os estudantes com deficiência deveriam “[...] ter um espaço, [...] participar de determinados momentos em sala [...] assistir um filme [...] educação física [...] intervalo, [...] mas dentro de sala de aula [...] é um desrespeito com o nível cognitivo dele [...]" (PH). (Entrevista concedida em 03/06/2016)

A Política Nacional de Educação Especial na Perspectiva da Educação Inclusiva orienta que as escolas devam garantir o "[...] acesso ao ensino regular, com participação, aprendizagem e continuidade nos níveis [...] do ensino [...]" (BRASIL, 2008a, p. 14).

Esses propósitos serão alcançados quando os professores privilegiarem a sala de aula como local de aprendizagem de todos os estudantes. Por sua vez,

\footnotetext{
${ }^{6}$ Esporte adaptado, praticado com uma bola, o qual o PE adaptou, utilizando cano de PVC, para que o EA pudesse se orientar e jogar.
} 


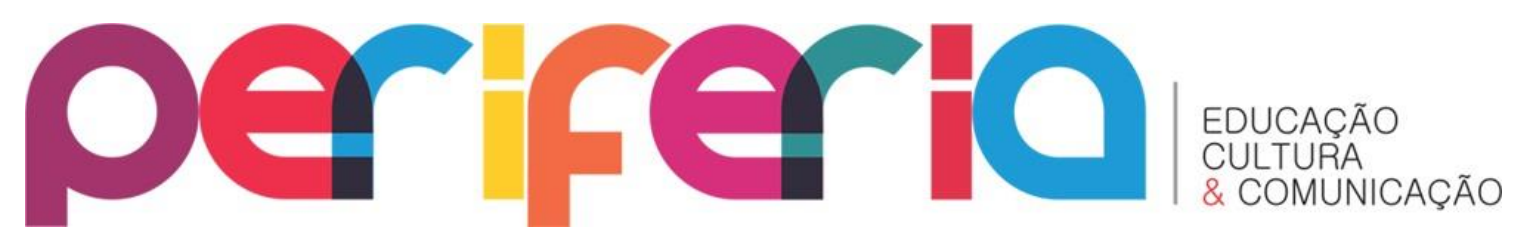

a escola precisará organizar suas atividades, de forma a oferecer, aos seus profissionais, condições para que desenvolvam suas práticas pedagógicas a favor da inclusão escolar.

\subsection{EIXO II: RELAÇÃO EDUCATIVA (PROFESSORES REGENTES/ PROFESSOR APE/ EA)}

Nas aulas de literatura, embora o EA não frequente as aulas e as mediações fiquem por conta do professor APE, observamos o reconhecimento das especificidades do EA por parte dos professores, quando o professor de literatura afirma: “[...] as vezes que nós conseguimos sentar para conversar, a gente teve umas ideias [...] nós passamos para a parte da educação especial [...] a ideia de procurar esses vídeos [...] dinâmicos [...]".

Quanto às questões pedagógicas, troca de informações sobre o EA, o PG afirmou que “[...] quando há os conselhos o professor fala [...] como que está o aluno [...] naquela disciplina e por aí dá para você ir vendo [...]”.

Quanto aos aspectos da relação didática entre o PLI I-II e o professor APE, percebemos esforço maior do segundo, confirmando-se quando o PLI I-II afirmou que o APE “[...] acaba buscando meios para assistir ele [EA] [...] exatamente a função dela [...]”. O que já fora evidenciado em Anjos, Andrade e Pereira (2009), ao discutirem a inclusão do ponto de vista dos professores, concluíram que:

A expectativa mais evidente com relação ao trabalho do professor que cuida do AEE, que atende nas salas de atendimento especializado, [...] é que ele trate apenas das questões referentes à educação dos alunos com deficiência. (p. 126).

O PAM apontou dificuldades na relação didática com o professor APE e o EA, ao afirmar que a interlocução é “[...] complicada pelo motivo da quantidade de aula, é uma aula só por semana, [...] um monte de obrigações [...] é feita, conforme as oportunidades [...].” (PAM). (Entrevista concedida em 06/07/2016) 


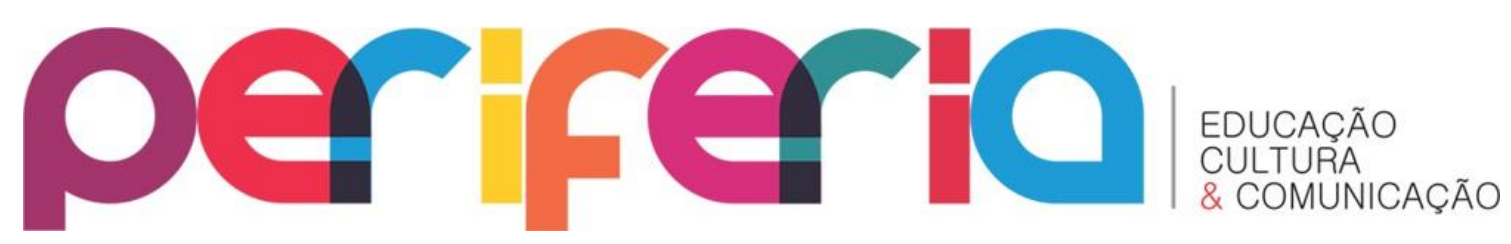

O referido professor não aponta suas práticas como relevantes, ressalta atendimentos paralelos, justificado pela: “[...] dificuldade do aluno em acompanhar o conteúdo normal [...]" (PAM, 06/07/2016).

O PG revelou com seus relatos, sentir-se menos responsável pela escolarização do EA, o que pode estar relacionado à falta de esclarecimento acerca da educação especial, ao afirmar: “[...] a gente recebe o aluno, não tem nenhuma orientação, [...] até mesmo do órgão que cuida dessas atividades, mandar já umas coisas diferentes para gente poder melhorar [...] então esse apoio que eu acho que falha [...]". Assim, o PG, ao mesmo tempo que centraliza atuação do professor APE na escolarização do EA, reclama por apoios para aprimorar suas práticas.

0 exposto revela fragilidades da formação docente e imprecisões das políticas públicas, ao mesmo tempo em que os professores são chamados à responsabilidade, a estes não são dados subsídios formativos e apoios para essa compreensão.

Mendes, Vilaronga e Zerbato (2014, p. 39) asseveram que a inclusão escolar impõe ao professor comum desafios, por isso, demandará “[...] apoio de outros profissionais da área da Educação Especial para a construção de práticas inclusivas [...]".

Quanto à relação educativa com o professor APE, o PEF destacou que as decisões acerca do processo escolar do EA são tomadas por meio das conversas nas aulas:

$[\ldots]$ foi numa dessas conversas que ela $[\mathrm{APE}]$ falou que $o$ L. estava regredindo na questão motora [...] A gente vê aqui na escola que, no caso a $S$. que acompanha, $[. .$. nós em sala [...] mas, se a família não tiver envolvida, $[\ldots]$ o aluno [...] não vai progredir (PEF). (Entrevista concedida em 15/06/2016)

Embora a escola e família sejam indispensáveis na inclusão escolar, não se pode considerar que as dificuldades serão resolvidas apenas sob esses esforços. Barros (2016, p. 107) considera que apesar de ser fundamental a 


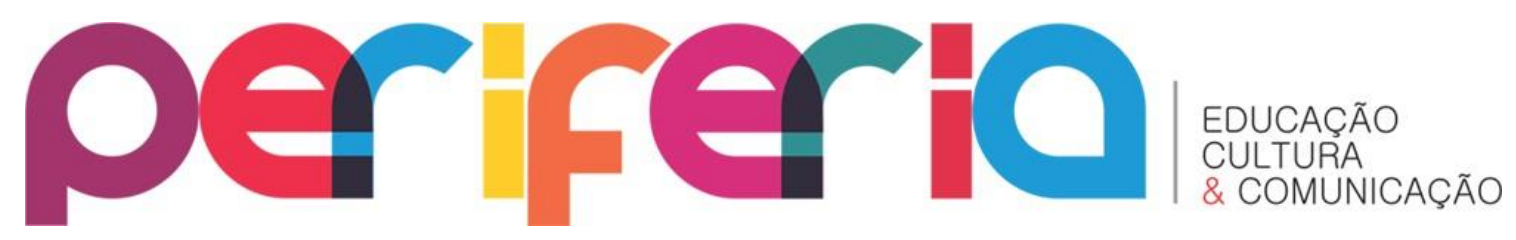

presença dos profissionais especializados, não podem ser "[...] substitutivos ao envolvimento de toda a escola e de políticas públicas que efetivamente minimizem as mazelas sociais que refletem no cotidiano escolar".

No contexto das aulas de matemática, o professor ressalta que as adaptações de atividades para o EA ocorrem "[...] quando é possível. Quando não é, é aquilo que eu te falei, atividade totalmente diferenciada [...]".

Embora a relação didática entre PM e professor APE apresente disparidades e certo comodismo do primeiro, quanto ao trabalho diferenciado diante dos estudantes com e sem deficiência, o PM reconhece a diversidade na sala de aula, ao afirmar:

[...] se você for pensar no aluno especial ou não, $[\ldots]$ todo mundo peca [...]. Você faz um planejamento pensando [...] numa sala homogênea, [...] colocam dois, três alunos com laudo numa sala de trinta [...] três aulas [...] por semana. [...] Você mastiga o conteúdo [...] não está certo. Inclusão é só no papel [...] (PM). (Entrevista concedida em 21/09/2016)

O referido professor reconhece que a inclusão escolar não ocorre como é prevista e aponta aspectos que justifica o insucesso, evidenciando o que apontaram Mendes, Vilaronga e Zerbato (2014, p. 63), que há “[...] um consenso que o sistema educacional [...] têm de ser reestruturadas para atender as novas demandas [...]. Evolui-se nas concepções, porém a escola tradicional com sua estrutura física, humana e profissional ainda não foi modificada".

Beyer e Santos (2006, p. 2) ao discorrerem sobre o projeto pedagógico que atenda a inclusão escolar pontuam que, “[...] temos encontros frequentes com professores [...] por um lado, observamos a atitude cética e crítica em relação à lei da inclusão escolar, e, por outro, a expectativa e busca por "fórmulas pedagógicas inclusivas", o que absolutamente não existe!"

Tais concepções foram observadas nos relatos do PM e PG respectivamente: 


\section{periferio}

[...] Inclusão é só no papel, [...] pra mim ela acaba não ocorrendo como deveria (PM). (Entrevista concedida em $21 / 08 / 2016)$

De parte da orientação, até mesmo do órgão que cuida dessas atividades, mandar já umas coisas diferentes para gente [...] (PG) (Entrevista concedida em 06/07/2016)

Ao mesmo tempo que demonstram descrença, os discursos sinalizam possíveis expectativas de mudanças.

No tocante às definições das abordagens didáticas com o professor APE, embora aconteçam nas próprias aulas ou intervalos, parecem ocorrer tranquilamente. Conforme o PQ-F, “[...] uma semana antes, a gente discute mais ou menos qual que vai ser o assunto trabalhado [...]".

Cabe ressaltar que os esforços de alguns professores para contemplar o EA são improvisados, haja vista que não há momentos para planejamentos conjuntos. Alguns professores desdobram para contemplá-lo; outros, justificam o não atendimento com discursos de que a escola não oferece condições para desenvolver práticas adequadas ou que sua formação não foi adequada.

Percebemos o esforço do PQ-F em estabelecer articulação e comunicação com o professor APE nas práticas pedagógicas, quando afirmou:

[...] Eu vou trabalhar tal conteúdo, então eu já falo para ela [APE] "Vou trabalhar com a maquete [...]" ela sempre me procura [...] "Eu tenho uma atividade [...] o que você acha?" [...] A gente troca informações assim [...]. (PQ-F). (Entrevista concedida em 09/07/2016)

Ainda que não disponha de tempo para elaborar planejamento partilhado com o professor $\mathrm{APE}$, os relatos do $\mathrm{PQ}-\mathrm{F}$ revelaram possibilidades de trabalho articulado. Observamos aspectos do ensino colaborativo, modelo de ensino no qual professores do ensino comum e especial trabalham colaborativamente, apontados por Gately e Gately (2001, p. 42), como um processo que passará por estágios de adaptações iniciais até atingir o nível de 


\section{periferio}

colaboração, a saber, "[...] o inicial (criação de tentativas para estabelecer o relacionamento) e o de comprometimento (comunicação mais frequente, abertura para diálogo, construção de nível de confiança necessário para a colaboração)".

Em análise da relação didática de docente e discente, ao descrever as práticas desenvolvidas, o professor de arte faz referência ao papel do professor APE e à participação do EA e demais estudantes, revelando sintonia entre professores e estudantes,

$[\ldots]$ a S. [APE] que faz os registros no caderno dele [EA], [...] a gente faz leitura coletiva, [...] ele [EA] participa, [...] dá opinião, né? durante a explanação do conteúdo eu faço uma pergunta para turma, o L. [EA] sempre quer participar [...] (PA). (Entrevista concedida em 20/06/2016)

Embora as adaptações sejam improvisadas, o referido professor reconhece a importância em repensar sua prática com o EA, “[...] às vezes, a gente dá uma adaptada assim na hora [...] porque tem a S. [APE] [...] ela auxilia bastante ele [...] mas estou falhando porque tem que ser bem pensado para atender ele [...]".

No contexto das aulas de história, o professor revelou dificuldades em inserir o EA nas aulas, sendo assim, privilegia a atuação do professor APE nas mediações didáticas, ao afirmar,

[...] eu não sei uma atividade adaptada que eu possa dar para o L., [...] eu vejo que a professora auxiliar, assim, ela [...] explica para ele [...] eu não sei como tirar dele um protagonismo da própria aprendizagem [...], para mim como professor é muito mais complicado (PH). (Entrevista concedida em 03/06/2016)

0 referido professor enfatiza a dificuldade em estabelecer relação educativa com o EA e obter seu "protagonismo". Torna-se difícil obter "protagonismo" quando se enfatiza a atuação do professor APE. 


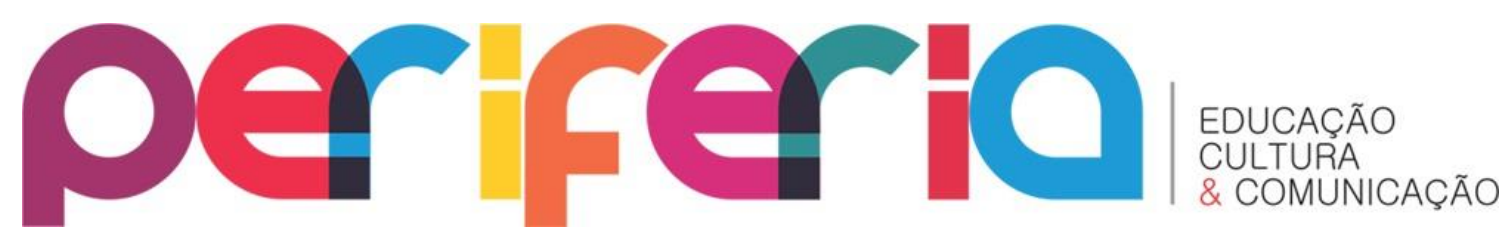

Capellini (2004, p. 210) pontua que: “[...] muitas escolas comuns se limitam a inserir o aluno na sala, colocando-o no papel de mero expectador, sem receber atenção e a estimulação que the são necessárias para o desenvolvimento intelectual e social".

O PH caracterizou sua interlocução com o professor APE como "satisfatória", ao ressaltar mediações didáticas com o EA, afirma que, "tem adaptações, [...] todas as aulas, [...] dou um texto separado para ele [EA] [...] que eu não dou para o resto da turma, [...] excelente a interação [...] Ela não chega atrapalhar meu trabalho, nem eu vou atrapalhar o dela [...]."

Tal atitude foi percebida nos estudos de Anjos, Andrade e Pereira (2009). Ao analisarem os discursos dos professores sob o ponto de vista da inclusão escolar, acerca das expectativas que estes têm do professor especializado, constataram que:

[...] há expectativa de que tal acompanhamento não interfira na ação dada como própria do professor de sala comum: aquela que se refere aos alunos "sem deficiência". Espera-se que assessore "de fora", sem se relacionar com as questões gerais da sala de aula (p. 126).

Nas aulas de língua portuguesa, a articulação entre o professor regente e professor APE se apresenta de forma satisfatória, a exemplo disso, destacase a atividade abaixo. Conforme o professor APE, o professor ia fazer:

[...] um trabalho de escrita e aí ela já falou, "S. [APE], como que eu posso inserir ele [EA]?" Eu falei: [...] “Ele é muito bom na interpretação" [...]. Ela já deu a ideia, "Vamos fazer um debate? [...]". O professor porque ele tem o saber [...] científico da matéria, $[\ldots]$ a gente já tem esse olhar [...] adaptado para educação especial, então, você tem que unir [...] (PROFESSOR APE). (Entrevista concedida em 01/06/2016)

As considerações do professor APE mostram indícios de uma prática colaborativa. Como pontuam Almeida e Machado (2010, p. 345), “[...] cada vez mais se tem trabalhado o princípio de que os professores não devem 


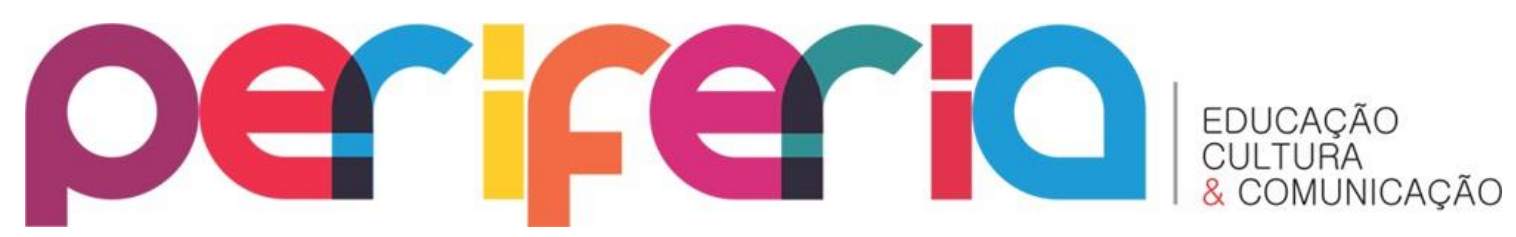

trabalhar sozinhos, mas em equipes [...] para melhorar a escolarização de todos os alunos".

Mendes (2008, p. 31) aponta o ensino colaborativo como estratégia para a construção de escolas inclusivas. Segundo a autora, tal estratégia possibilita tanto “[...] solucionar problemas relacionados ao processo de ensino e aprendizagem dos alunos com deficiência, quanto para o desenvolvimento pessoal e profissional dos educadores".

Os instrumentos de mediação influenciam sobremaneira a relação educativa e aspectos desta mediação foram observados em uma aula de língua portuguesa, quando o professor trabalhou o gênero textual (memórias). 0 professor, na ocasião, explanou e discutiu acerca do gênero e houve contribuições de estudantes comuns e EA na aula.

Quanto à comunicação com os professores, o professor APE ressaltou que embora os primeiros demonstrem dúvidas acerca de como trabalhar com o EA, não há iniciativas da parte dos docentes. Conforme o professor APE, “[...] nós (professores especializados) que procuramos eles (professores regentes) [...] muitas vezes, a gente vai procurar, eles falam: "Puxa! Eu estava com uma dificuldade nisso, não sei o que eu ia fazer" [...]".

Ressaltamos que, da mesma forma que o professor regente deve assumir os estudantes com deficiência como seus, o professor da educação especial deve fazer o mesmo quanto aos demais estudantes, sob o primado de estabelecer um trabalho comum.

Quando os professores entendem que são responsáveis por todos os alunos, as atividades podem ser planejadas em conjunto, com a adaptação específica para o aluno-alvo. Se a atividade for idealizada para o aluno-alvo sem base nas atividades de sala, necessariamente vai acontecer uma aula paralela [...]. (VIRALONGA, 2014, p. 88-89).

As práticas com o EA merecem olhar mais atento dos professores regentes e professor APE, na tentativa de pensar estratégias que congreguem 


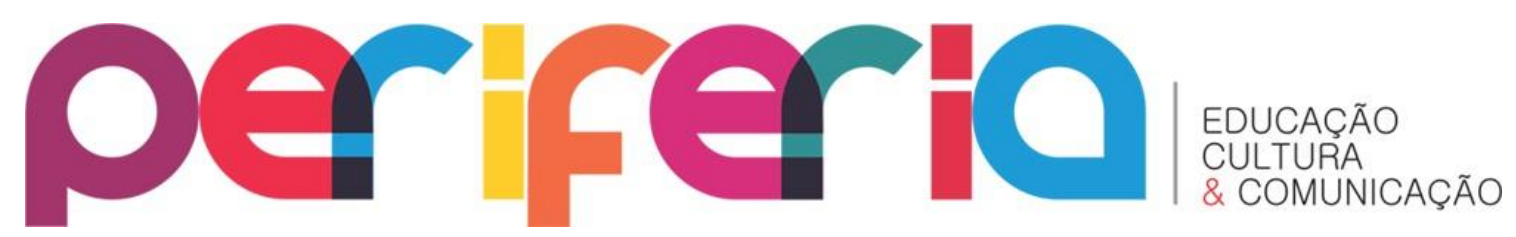

conhecimentos acadêmicos às adaptações para contemplar a participação do EA.

\subsection{EIXO III: INSTRUMENTOS DE MEDIAÇÃO DIDÁTICA}

Embora o EA não frequente as aulas de literatura, observamos instrumentos de mediações utilizados, até porque é necessário atribuir-lhe nota. Contudo, o professor ressalta que "[...] procuro as atividades que tenham alguma coisa em relação a vídeo para que ele possa assistir, ouvir e tentar produzir alguma coisa, [...]". O PL descreve duas atividades com vídeo para o EA, mediadas pelo professor APE, como avaliações:

[...] o apólogo de Machado de Assis, que fala sobre os seres inanimados que conversam entre si e outra agora sobre denotação e conotação, que também fala como que um vem do dicionário e o outra é essa linguagem mais do dia a dia, [...] (PROFESSOR DE LITERATURA). (Entrevista concedida em 06/07/2016)

No contexto das aulas de língua inglesa I e II, este professor afirmou que, pelo fato da professor APE não dominar o idioma e o conhecimento do EA não ser compatível com o nível da etapa escolar, as avaliações são em português. Conforme o PLI I-II: “[...] o problema do L. é que [...] não tem como eu trabalhar [...] na língua estrangeira [...] ele não tem conteúdo para isso".

Ao mesmo tempo em que admite ter dificuldade, o PLI I-II demonstra preocupações com sua prática. Tais preocupações são apontadas por Padilha (2007, p110) em encontros com professores e estudantes que se preparam para a docência, por se verem:

[...] ora obrigados a realizar uma proeza pedagógica sem sequer saber como; ora culpados por não estarem sendo solidários [...] com aqueles que aprendem diferente, [...] ora se sentem incompetentes por não estarem conseguindo que todos os seus alunos aprendam [...] . 


\section{periferio}

O relato do PLI I-II revelou uma sequência fechada de procedimentos didáticos ao citar uma atividade, excluindo a participação do EA: “[...] são atividades que os alunos vão usar o dicionário, [...] em grupo, vão se ajudar, [...] fazer uma tradução, completar uma folha, tem toda uma sequência nisso, que a condição dele não permite que ele faça".

O EA apresenta defasagens de conteúdos e que necessitam de adaptações para serem apreendidos. No entanto, a escola apresenta uma sequência curricular pré-estabelecida, em que os limites e possibilidades não são considerados.

No que tange às adaptações e flexibilizações de conteúdos, Beyer (2006) assevera que:

O desafio é construir e pôr em prática no ambiente escolar uma pedagogia que consiga ser comum e válida para todos os alunos [...] atender os alunos cujas situações pessoais e características de aprendizagem requeiram uma pedagogia diferenciada (BEYER, 2006, p.76).

Nas aulas de aplicações matemáticas, o instrumento de mediação central é o simulado. Segundo o professor, "toda aula tem um simulado, numa aula a gente aplica, na outra a gente corrige [...]", o EA não os realiza, porque seus conhecimentos não estão de acordo com o nível exigido.

A organização das etapas escolares por nivelamento, assim como, a dinâmica das aulas de matemática, no contexto analisado, mostrou-se excludentes e impossibilitaram a participação do EA. Assim, é necessário que a escola:

[...] repense a sua função curricular, [...] as formas de aprendizagem a partir das inovações metodológicas e didáticas [...] com vistas a atender crianças $\mathrm{e}$ jovens provenientes de cultura cada vez mais diversificadas [...] (JESUS, 2009, p. 9). 


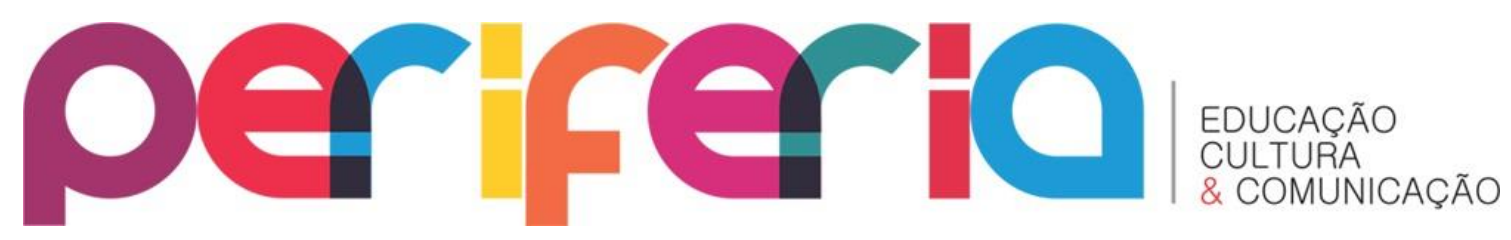

As atividades e avaliações realizadas pelo EA nas aulas de geografia são as mesmas que os estudantes comuns fazem, diferenciando apenas na quantidade. Conforme este professor,

[...] as atividades, a professora, pega comigo e ela vai falando com ele e ele vai dando as respostas [...] ela que escreve, [...] duas, três questões dependendo da quantidade que a sala faz para que dê tempo [...] (PROFESSOR DE GEOGRAFIA). (Entrevista concedida em 06/07/2016)

Como instrumento de mediação nas aulas de educação física, foi utilizado o quadro negro para explanar conteúdos para a turma e para o EA, o PEF utilizou recortes e colagens, com auxílio do professor APE. Na sequência, o professor de educação física demonstrou exercícios de alongamento com o EA. Acerca dos instrumentos de mediação, o docente ressaltou:

[...] em sala de aula, eu utilizo textos, né? Onde eles copiam, nós fazemos as discussões, aí depois atividade avaliativa, [...] sala de informática para fazer a pesquisa [...] atividade avaliativa e na quadra. Porque ele entende a parte teórica [...] (PROFESSOR DE EDUCAÇÃO FÍSICA). (Entrevista concedida em 15/06/2016)

Em uma aula de matemática, PM trabalhou o conteúdo de funções com gráficos, explanou no quadro e propôs exercícios à turma. Paralelo a isso, com o EA, o professor APE fez revisão dos conteúdos de química e aplicou a prova no laboratório de ciência. Assim, percebemos que houve um direcionamento do professor especializado para os conteúdos que considera pertinentes, portanto, o APE assume a escolarização do EA.

Ao investigar a relação de intérpretes de Libras e professores que atuam com estudantes surdos, Oliveira (2012, p. 105-106), pontuou que os intérpretes “[...] se sentiram responsáveis pelas dificuldades e incompreensões dos alunos surdos, assumindo para si a tarefa de ensinar, [...] assumindo, de certa forma, o papel que seria dos professores". 


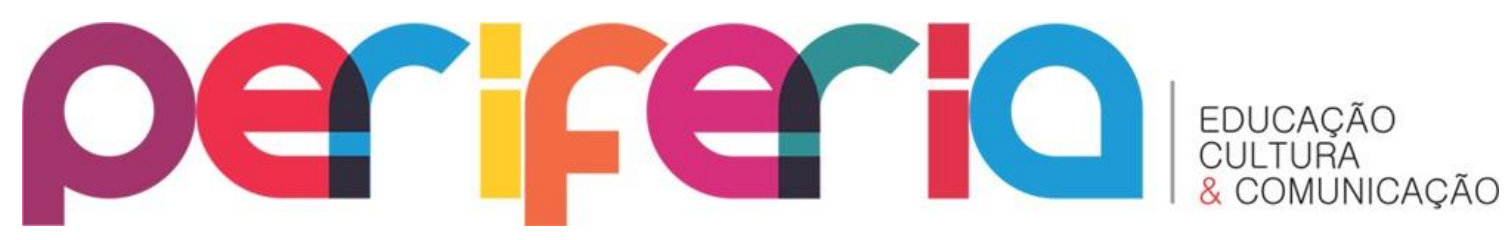

Os instrumentos de avaliação considerados pelo PM diante da escolarização do EA têm enfoque: "[...] na questão oral, na participação [...]". Este professor acrescenta que não é necessário o EA realizar as provas formais, pois: "[...] tem o registro do portfólio7. O PM afirmou que faz atividades adaptadas: “[...], mas na maioria das vezes ela [APE] faz [...] quando dá pra encaixar algo no conteúdo, sempre encaixo, agora quando não dá, a gente faz diferenciada".

Observamos que as possibilidades de aprendizagem do EA devem se adaptar ao currículo comum, e não o contrário. As orientações das Diretrizes Nacionais para a Educação Especial na Educação Básica ressaltam que a dificuldade de aprendizagem desses estudantes “[...] requer respostas educativas adequadas, que abrangem graduais e progressivas adaptações de acesso ao currículo, bem como adaptações [...]" (BRASIL, 2001b, p. 58).

Ao analisar os instrumentos de mediação no contexto das aulas de química e física, o professor demonstrou que prevalecem os recursos audiovisuais ao exemplificar uma atividade:

[...] mostrei os impactos de acidentes, [...] depois com a ajuda dela [APE] [...] ele fez uma produção muito boa, [...] pegou a parte da velocidade da física, [...] associou isso às lei de Newton [...] (PROFESSOR DE QUÍMICA E FÍSICA). (Entrevista concedida em 09/07/2016)

Depreendemos da abordagem utilizada pelo referido professor uma resposta de apreensão do EA diante da atividade proposta, ou seja, a partir da mediação do professor e do APE houve sistematização de conhecimento, dentro das possibilidades do EA.

No contexto das aulas de arte, ao trabalhar a técnica de desenho de foto sobre o carbono, o professor APE e PA decidiram delimitar a moldura com cola quente, para que o EA fizesse os traços sem ultrapassar a linha. Houve implementação dos instrumentos, para contemplar o EA na atividade.

\footnotetext{
7 Portfólio refere-se a um caderno, no qual consta atividades adaptadas na maioria das vezes propostas pelo APE, bem como as anotações e intervenções realizadas com o estudante.
} 


\section{of
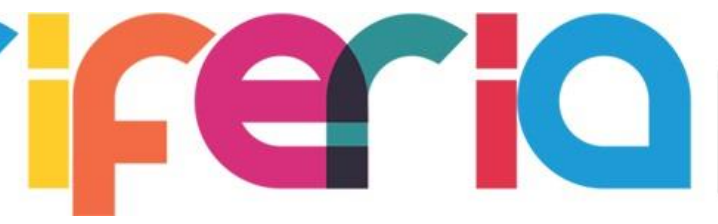

A atitude caracterizou-se em parceria dos docentes, apontada por Capellini (2004, p. 88) como ensino colaborativo, modelo de trabalho, no qual os docentes "[...] compartilham a responsabilidade de planejar e de implementar o ensino e a disciplina da sala de aula".

Faz-se necessário a junção dos conhecimentos propostos pelos professores comuns em termos de conteúdos e a especialização dos professores do ensino especial, para se definir estratégias que contemplem a participação e aprendizagem do EA, contudo, há que se repensar essa parceria,

[...] uma vez que tanto o domínio de conteúdos, quanto o domínio de estratégias de ensino dos professores especialistas não tem conseguido garantir a qualidade do processo ensinoaprendizagem de todos os nossos alunos com e sem deficiência (CAPELLINI, 2004, p. 92).

Apenas a atuação dos professores comuns e especializados não garante a aprendizagem dos estudantes, inclusive os com deficiência, mas determinam mudanças. Tais mudanças devem ocorrer no âmbito das políticas públicas, das escolas e gestão escolar.

$\mathrm{O} \mathrm{PH}$ revelou que tem dificuldades em eleger instrumentos didáticos para trabalhar com o EA, devido à sua especificidade, mas não com outros estudantes com deficiência, podendo ser observado no relato abaixo:

[...] os outros [estudantes com deficiência] assim, se tenta fazer uma cruzadinha, uma atividade $[. .$.$] lúdica, [. .$.$] no caso$ do L. [EA], como ele tem um problema motor, [...] ele não vai desenvolver uma escrita, [...] fica mais da parte da professora [APE] [...] (PROFESSOR DE HISTÓRIA). (Entrevista concedida em 03/06/2016)

O exposto aponta o enfoque na limitação, em que a escrita é central, aspecto que impossibilita avanços acadêmicos, caracterizando o que afirmam Lehmkuhl e Michels (2015, p. 66): “[...] tendo o diagnóstico clínico como 


\section{Pa COC}

definidor de suas possibilidades acadêmicas, responsabilizando tais sujeitos pelo seu próprio fracasso".

No contexto de aulas de língua portuguesa, observamos, o computador como instrumento de mediação. O PLP orientou a turma e o APE sobre como proceder. A atividade consistiu em questionário, o APE leu as questões e o EA as respondeu, o APE fez os registros no computador. Apesar da tecnologia configurar como recurso promissor, especificamente para a educação especial, não podemos reduzi-la a transposição do que seria proposto no livro didático ou quadro.

Outro instrumento didático utilizado na aula de língua portuguesa consistiu em uma atividade de leitura. O PLP apresentou alguns livros, solicitou que os estudantes escolhessem um poema, fizessem leitura e descrição do gênero, destacassem as palavras complexas e procurassem os significados no dicionário.

A leitura como instrumento de mediação é apontada por Almeida e Machado (2010) como favorecedora da aprendizagem e socialização. Ao avaliar os efeitos desta prática pautada no ensino colaborativo, os autores concluíram que atividades dessa natureza:

[...] tornam-se um rico meio de promover o aperfeiçoamento da mesma, bem como fortalecer a socialização, ainda mais se essas práticas forem construídas por meio de colaboração entre professor e professor de educação especial. (ALMEIDA; MACHADO, 2010, p. 350).

O professor APE pontuou que os professores regentes têm contemplado a participação dos estudantes com deficiência, no intuito de inseri-los nos contextos das aulas, embora não disponibilizem os conteúdos antecipadamente para que se inteire do assunto. Conforme o professor APE: "[...] o certo é eles mandarem o planejamento anteriormente para gente, mas [...] para não dizer nunca, [...] um ou dois professores têm essa preocupação [...]". 


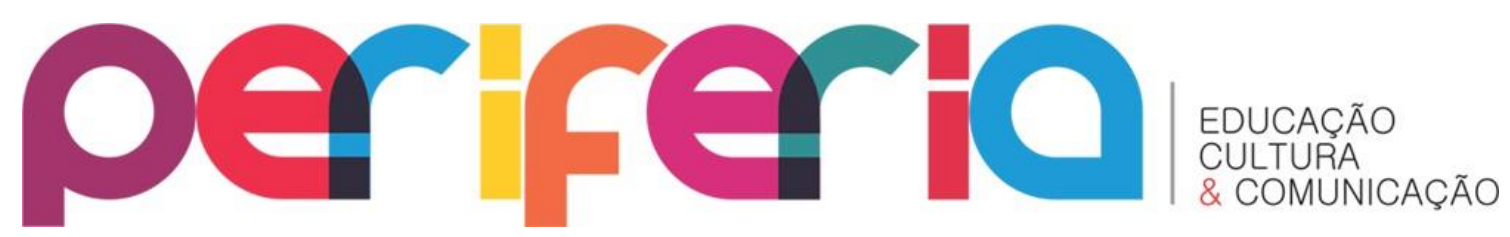

Crippa (2012, p. 63) alerta que "[...] a escola tem resistido à mudança, porque as situações que promovem o desafio da diversidade mobilizam os educadores a mudar suas práticas e a entender as novas possibilidades educativas para inclusão".

Embora os professores investigados tenham demonstrado insuficiências nas práticas para contemplar a escolarização do EA, sob os argumentos de não ter formação adequada, não dispor de tempo para dialogarem com o professor APE, os mesmos apontaram direções para discussões futuras, a saber, maior carga horária de planejamento, menos estudantes por sala, apoio de outros setores, formações continuadas, dentre outras.

\section{CONSIDERAÇÕES SOBRE O ESTUDO}

O presente estudo investigou as (re)ações dos professores regentes e do professor especializado na escolarização de um estudante com deficiência. Os esforços empreendidos possibilitaram refletir sobre as práticas docentes na sala de aula.

A despeito dos inúmeros documentos legais definirem 0 apoio educacional especializado, matrícula e acesso à aprendizagem na escola, a escolarização aos estudantes com deficiência, ainda carrega marcas de um trabalho didático que não leva em conta as necessidades educacionais dos mesmos. Nesse estudo, as ações dos professores regentes eram direcionadas aos estudantes sem deficiência, enquanto que as ações do professor APE contemplavam apenas o EA, ainda que atuassem em um mesmo espaço físico, no qual se deveria primar pela aprendizagem de todos.

Cabe ressaltar que a organização pedagógica da escola, não tem proporcionado que as práticas sejam eficazes, uma vez que não disponibiliza condições concretas para que se desenvolvam estratégias de aprendizagem adequadas. 0 mesmo se aplica a falta de tempo para que os professores possam discutir e panejar ações que beneficiariam a escolarização desses 


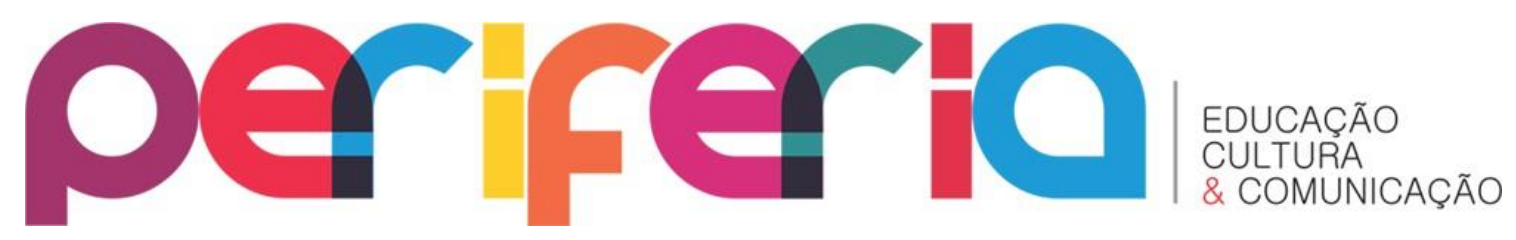

estudantes, tal como preconizam as orientações previstas nas normas que expressam as políticas públicas para a educação especial.

Outro fator que permeou os relatos dos professores regentes foi a dificuldade em definir estratégias que contemplem o EA, sendo que a responsabilidade recai na atuação do professor APE. É o professor APE, aquele que conduz a ação didática para o EA, enfatizando os conteúdos que considera relevantes.

Em meio às ações dos professores algumas reações positivas foram observadas, e no assoberbado cotidiano, alguns dispunham de tempo para conversar com o professor APE, acerca de estratégias de ensino para contemplar o EA, revelando que práticas colaborativas são possíveis de serem estabelecidas e/ou implementadas.

Há um discurso generalizado dos professores de assistência, acolhimento, na tentativa de ajudar o EA, no que for possível, quando possivel. Nesse interim, presume-se que os processos avaliativos são ignorados, pois não foram observadas metas de aprendizagem para o EA, nem referência de objetivos nas práticas pedagógicas com o EA.

Quantos às (re)ações redesenhadas nas práticas dos profissionais para contemplar estudantes com deficiência, a literatura investigada nesse estudo apontou experiências positivas envolvendo o ensino colaborativo, no qual se conjuga a atuação do professor regente e especializado para mediar a inclusão escolar, com resultados significativos tanto para a articulação docente, aprendizagem dos estudantes, quanto para a formação profissional.

Não se pretendeu apontar análises conclusivas, mas provocar discussões posteriores, que investiguem como tem se estabelecido a articulação de professores regentes e especializados em outros contextos escolares, identificar os limites e possibilidades dessa atuação. 


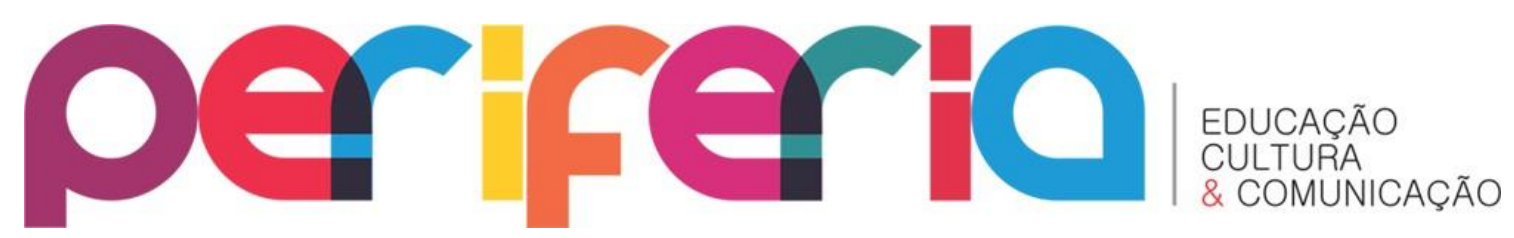

\section{REFERÊNCIAS}

ANJOS, H. P.; ANDRADE, E. P.; PEREIRA, M. R. A inclusão escolar do ponto de vista dos professores: o processo de constituição de um discurso. Revista Brasileira de Educação, Rio de Janeiro, v. 14, n. 40, p. 116-129, Abr.2009.

ALMEIDA, C. E. M. A educação especial nos cursos de licenciatura das universidades de Mato Grosso do Sul. 2005. 166p. Dissertação (Mestrado). Universidade Católica Dom Bosco, Campo Grande, 2005.

ALMEIDA, M. A.; MACHADO, A. C. M. Parceria no contexto escolar: uma experiência de ensino colaborativo para educação inclusiva. Revista de Psicopedagogia, São Paulo, v.27, n.84, p. 344-351, 2010.

ALVES, G. L. O trabalho didático na escola moderna: formas históricas. Campinas, SP: Autores Associados, 2005.

BEYER, H. O. Da integração escolar à educação inclusiva: implicações pedagógicas. In: BAPTISTA, C. R. (Org.) Inclusão e Escolarização: múltiplas perspectivas. Porto Alegre: Mediação, 2006. p. $73-81$.

BEYER, H. O.; SANTOS, T. A. O Projeto da educação inclusiva: perspectivas e princípios de implementação. In: Anped Sul "Pesquisa em Educação: Novas Questões?”, 5, Santa Maria, 2006. Anais..., Santa Maria, 2006.

BRASIL. Lei $\mathrm{n}^{\circ}$ 4.024, de 20 de dezembro de 1961. Fixa as diretrizes e bases da educação nacional. Diário Oficial da União, Brasília, 1961.

BRASIL. MEC. Lei $\mathrm{n}^{\circ}$ 9394, de 20 de dezembro de 1996. Dispõe sobre as diretrizes e bases da educação nacional. Diário Oficial da União, Brasília, 1996.

BRASIL. Conselho Nacional de Educação. Resolução $n^{\circ} 2$, de 11 de setembro de 2001. Diretrizes Nacionais para a Educação Especial na Educação Básica. Diário Oficial da União, Brasília, 2001b.

BRASIL. Ministério da Educação/SEESP. Política Nacional de educação especial na perspectiva da educação inclusiva. Brasília: MEC/SEESP, 2008 ${ }^{\text {a }}$ Disponível em: <http://portal.mec.gov.br/seesp/arquivos/txt/brasil.txt>. Acesso em: 10 fev.2016.

CAMPO GRANDE. Resolução SEMED ${ }^{\circ}$ 154, de 21 de fevereiro de 2014. Dispõe sobre a Educação dos Alunos com Deficiência, Transtornos Globais do Desenvolvimento e Altas Habilidades/ Superdotação em todas as Etapas e 


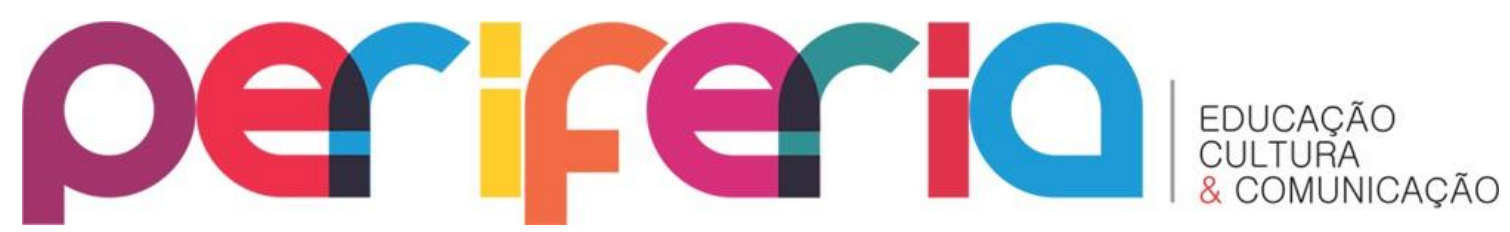

Modalidades da Educação Básica da rede Municipal de Ensino de Campo Grande - MS. Diário Oficial, Campo Grande, n. 3.970, p. 4-5, 11 mar. 2014.

CAPELLINI, V. L. M. F. Avaliação das possibilidades do ensino colaborativo no processo de inclusão escolar do aluno com deficiência mental. 2004. 300f.. Tese (Doutorado em Educação). Universidade Federal de São Carlos, São Carlos, 2004.

CRIPPA, R. M. O ensino colaborativo como uma contribuição para a educação inclusiva. 2012. 117f. Dissertação (Mestrado em Educação). Universidade de Uberaba, Uberaba, 2012.

FREITAS, A. O. Atuação do professor de apoio à inclusão e os indicadores de ensino colaborativo em Goiás. 2013. 123f. Dissertação (Mestrado em Educação). Universidade Federal de Goiás, Catalão, 2013.

GATELY, S. E.; GATELY, F. J. Understanding coteaching components. Teaching Exceptional Children, n. 33, p. 40-47, 2001.

HONNEF, G. Trabalho Docente Articulado: A Relação entre a Educação Especial e o Ensino Comum. In: Anped Sul, 10, Universidade Federal de Santa Catarina, Florianópolis, outubro de 2014. Anais..., Florianópolis, 2014.

JESUS, D. M. Vozes e narrativas na ação grupal: trajetórias de formação de professores pesquisadores na perspectiva da inclusão escolar. In: JESUS, D. M. de; BAPTISTA, C. R.; BARRETO, M. A. S. C.; VICTOR, S. L. Inclusão, práticas pedagógicas e trajetórias de pesquisa. Porto Alegre: Mediação, 2009. p. 166175.

LEHMKUHL, M.S.; MICHELS, M.H. A Política de Formação de Professores do Ensino Fundamental para Atender Alunos da Educação Especial. Educação $e$ Fronteiras, Dourados/MS, v.5, n.13 p.7-20, maio/ago. 2015.

MENDES, E. G. Perspectivas para a construção da escola inclusiva no Brasil. In: PALHARES, M.S; MARTINS, S. C. (Orgs). Escola Inclusiva. São Carlos: EDUFSCAR. 2002.

MENDES, E. G. Pesquisas sobre inclusão escolar: Revisão da agenda de um grupo de pesquisa. Revista Eletrônica de Educação, São Carlos, v.2, n. 1, p 325, jun. 2008.

MENDES, E.G. VILARONGA, A.A.R. ZERBATO, A.P. Ensino colaborativo como apoio à inclusão escolar: unindo esforços entre educação comum e especial. São Carlos-SP: EdUFSCar, 2014. 


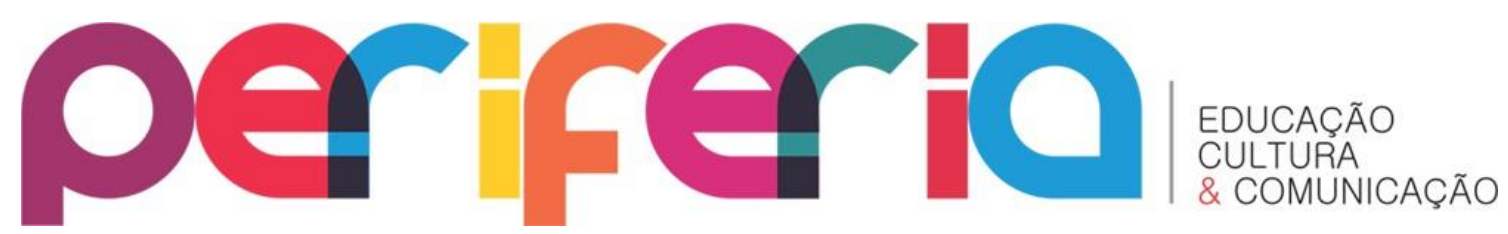

NERES, C. C. A Escolarização dos Alunos com Deficiência e a Inclusão Escolar: aproximações com as práticas escolares. 2015. Tese (Pós-Doutorado). Universidade Federal de Mato Grosso do Sul, Corumbá, 2015.

OLIVEIRA, W. D. de. Estudos sobre a Relação entre Intérprete de Libras e o Professor: implicações para o ensino de ciências. 2012. 115f. Dissertação (Mestrado em Educação). Universidade Federal de Goiás, Goiânia, 2012.

PADILHA, A. M. L. O que fazer para não excluir Davi, Hilda, Diogo. In: GÓES, M. C. R. de; LAPLANE, L. F. de. (Org.). Políticas e práticas de educação inclusiva. 2 ed. Campinas-SP: Autores Associados, 2007. (Coleção Educação Contemporânea).

VILARONGA, C. A. R. Colaboração da educação especial em sala de aula: formação nas práticas pedagógicas do coensino. 2014. 216f. Tese (Doutorado em Educação). Universidade Federal de São Carlos, São Carlos, 2014.

ZANATA, E. M. Práticas pedagógicas inclusivas para alunos surdos numa perspectiva colaborativa. 2004. 198f. Tese (Doutorado em Educação). Universidade Federal de São Carlos, São Carlos, 2004. 